\title{
ASPECTOS GERAIS DA INIBIÇÃO NA OBRA DE D. W. WINNICOTT
}

\author{
GENERAL ASPECTS INHIBITIONS IN THE D. W. WINNICOTT'S WORK \\ ASPECTOS GENERALES DE LA INHIBICIÓN EN LA OBRA DE D. W. WINNICOTT
}

\author{
Bruna Praxedes Yamamoto* \\ Leopoldo Pereira Fulgencio Junior ${ }^{* *}$
}

\begin{abstract}
RESUMO
Este artigo tem como objetivo explicitar a gênese e os efeitos da inibição no desenvolvimento do indivíduo, do ponto de vista da obra de Winnicott. Para tanto, foi realizado um estudo teórico, com uma análise conceitual e estrutural da obra do autor, buscando mostrar como ele compreendeu a inibição. Neste estudo, foi possível distinguir diversos tipos de inibição, tais como dos instintos, da agressividade, do brincar, entre outros. Nas considerações finais, salientamos que as fases mais primitivas do desenvolvimento emocional são as mais suscetíveis ao uso da inibição como um mecanismo de defesa contra a angústia, logo a provisão ambiental tem uma importância decisiva. É importante ressaltar que, no entanto, nem sempre a inibição resulta numa patologia, uma vez que Winnicott acredita que somente uma criança saudável é capaz de organizar defesas, inclusive a própria inibição, para lidar pontualmente com os seus medos de ser e estar no mundo.
\end{abstract}

Palavras-chave: Inibição. Angústia. Defesa. Saúde. Patologia.

\begin{abstract}
The aim of this article is to clarify the genesis and effects of inhibition in the individual's emotional development, from the point of view of Winnicott's work. It is a theoretical study with a conceptual and structural analysis of Winnicott's work, trying to show how he understood inhibition. In this study, we could clarify different types of inhibition, for example: inhibition of instincts, inhibition of play and others. In the conclusion, we emphasize that the beginnings of the individual's emotional development are the phases that are more susceptible for inhibition against anxiety to appear. Then, the environmental provision is of decisive importance. It is important that we
\end{abstract}

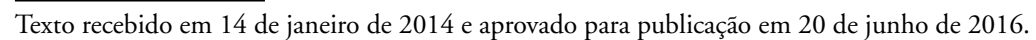

* Professora mestra e coordenadora do Curso de Psicologia da Faculdade Anhanguera de Taboão da Serra. Endereço: Rodovia Régis Bittencourt, 199 - Centro, Taboão da Serra-SP, Brasil. CEP: 06768-000. E-mail: bruna.yamamoto@anhanguera.com.

** Professor doutor do Departamento de Psicologia Escolar e do Desenvolvimento do Instituto de Psicologia da Universidade de São Paulo. Endereço: Av. Professor Mello de Morais, 1721 - Butantã, São Paulo-SP, Brasil. CEP: 05508-030. E-mail: lfulgencio@usp.br. 
note that inhibition is not always result in pathology, because Winnicott believed that only a healthy child can organize defenses, such as inhibition, to deal promptly with their fears of being and to be in the world.

Keywords: Inhibition. Anguish. Defense. Health. Pathology.

\section{RESUMEN}

Este artículo trata de explicar la génesis y los efectos de la inhibición en el desarrollo de la persona, desde el punto de vista de la obra de Winnicott. Para esto, se realizó un estudio teórico con un análisis conceptual y estructural de la obra del autor, intentando mostrar cómo él entendía la inhibición. En este estudio, fue posible distinguir diferentes tipos de inhibición, tales como la de los instintos, de la agresividad, del juego, entre otros. En la conclusión, observamos que las etapas más tempranas del desarrollo emocional son las más susceptibles a la utilización de la inhibición como un mecanismo de defensa contra la ansiedad, por lo que la provisión ambiental es de una importancia decisiva. Es importante destacar, sin embargo, que no siempre la inhibición desemboca en una patología, ya que Winnicott cree que sólo un niño sano es capaz de organizar las defensas, incluyendo la propia inhibición, para hacer frente con prontitud a sus temores de ser y estar en el mundo.

Palabras-clave: Inhibición. Ansiedad. Defensa. Salud. Patología.

\section{INTRODUÇÃO}

D iversos campos do saber, tais como a Psiquiatria, a Psicologia escolar, a Psicologia cognitiva-comportamental e a Psicanálise, têm abordado de diferentes maneiras o tema inibição, chegando a nomear o fenômeno de inibição intelectual, debilidade mental, um tipo de transtorno global do desenvolvimento, Transtorno de Déficit de Atenção - Hiperatividade (TDAH), etc.

$\mathrm{Na}$ Psicanálise, esta como sendo, por assim dizer, uma Psicologia do inconsciente, esse tipo de fenômeno também já foi reconhecido, de um modo que se procura considerar a inibição como um mecanismo de defesa contra as angústias que advêm das relações inter-humanas. Freud (1925/2006), por exemplo, descreve que as inibições são "restrições das funções do ego que foram ou impostas como medida de precaução ou acarretadas como resultado de um empobrecimento de energia" (p. 111).

Anna Freud (1946), por sua vez, também pesquisou esse fenômeno e ainda fez uma distinção entre inibição e restrição do ego, visto que, na primeira, o 
indivíduo se defende "contra a tradução em ação de um determinado impulso instintivo proibido" (p. 87), isto é, o ego se defende contra seus próprios processos internos. Já na restrição do ego, as situações externas desagradáveis são rechaçadas, porque poderiam remeter a revivescência de situações do passado, ou seja, o ego se defende contra os estímulos externos.

Esse quadro descritivo sobre a inibição pode ser compreendido como um problema de mau funcionamento neurofisiológico, uma disfunção cognitiva, ou ainda, na perspectiva psicanalítica clássica, um tipo de mecanismo de defesa contra angústias advindas da administração da vida instintual nos relacionamentos interpessoais (Santiago, 2005)

No entanto, não há, na obra de Winnicott, um artigo específico sobre a inibição, sua gênese, os tipos de inibição e sua finalidade. Porém se encontram diversas citaçôes sobre o fenômeno entre os textos que o autor escreveu que, reunidas, podem nos fornecer uma compreensão desse elemento.

\section{A INIBIÇÃO NA TEORIA DO DESENVOLVIMENTO DE WINNICOTT}

No decorrer da obra de Winnicott, encontram-se diversas passagens em que o autor menciona a importância da mãe no período inicial do desenvolvimento do bebê. Ele acredita que serão a partir das falhas realizadas pela mãe e pelo ambiente que um distúrbio, e até mesmo uma inibição, poderá ocorrer no percurso do desenvolvimento da criança. Assim, diz Winnicott (1945c/2000):

É especialmente no início que as mães são vitalmente importantes, e de fato é tarefa da mãe proteger o seu bebê de complicaçóes que ele ainda não pode entender, dando-lhe continuamente aquele pedacinho simplificado do mundo que ele, através dela, passa a conhecer. [...] Toda falha relacionada à objetividade, em qualquer época, refere-se à falha nesse estágio do desenvolvimento emocional primitivo (p. 228).

Pode-se compreender que essa tarefa essencial no início do desenvolvimento do bebê faz parte do estágio de dependência absoluta, em que o bebê necessita do auxílio da mãe para ser e continuar sendo, momento em que não têm ainda maturidade nem para reconhecer a dependência e nem para ter objetividade sobre o que necessita. Nesse estágio, a provisão ambiental é realizada naturalmente, de acordo com as necessidades da criança, e algumas mães conseguem atender satisfatoriamente às necessidades do ego de seus bebês (Winnicott, 1965a/1983), fornecendo uma adaptação que Winnicott denomina de suficientemente boa com a mãe estando num período de preocupação materna primária. 
Se tudo corre bem nesse desenvolvimento, a criança passa, pouco a pouco, de um estado não integrado, um estado em que se amalgama com a mãe, para um estado em que está integrada num EU SOU diferenciado do mundo.

Assim, as crianças que são integradas e socializadas são capazes de sofrer de inibiçôes e organizações de defesas contra a ansiedade. Tais defesas também podem ser estabelecidas no interior da personalidade da criança, quando as ansiedades e os conflitos são tão dolorosos que ela precisa organizar defesas internas contra esses fatores (Winnicott, 1993/1999).

Pode-se considerar também que um dos motivos para o surgimento de futuros problemas, assim como o surgimento de uma inibição, é a ruptura de dissonância entre a criança e seu lar. Winnicott (1939/2012) acredita que:

É bem possível, para uma criança de qualquer idade, sentir-se triste ou perturbada ao ter que deixar o lar, mas o que desejamos sublinhar é que, no caso de uma criança menor, essa experiência pode significar muito mais do que a experiência real de tristeza. Pode, de fato, equivaler a um blackout emocional e levar facilmente a um distúrbio grave do desenvolvimento da personalidade, distúrbio esse que poderá persistir por toda a vida (p. 10, grifo do autor).

Pode-se incluir a inibição como um desses distúrbios nesse período. Tal ocorrência pode surgir no período inicial do desenvolvimento da criança, uma vez que uma parte de si que estava se integrando, pelas experiências daquele ambiente, perde a sustentação necessária e não se integra ou se desintegra por essa ruptura (Winnicott, 1939).

Nessecontexto, devemosapontarduassituaçôes distintas paracompreendermos, por sua vez, dois processos distintos da inibição como mecanismo de defesa:

a) o que ocorre nas fases mais iniciais, quando não há sintonia entre as necessidades do bebê e a função materna; e

b) o que ocorre após a conquista da integração que diferencia o EU do mundo. Assim, Winnicott (1948/2000, p. 242) compreende que "algumas das inibições, no entanto, surgem logo no início. O bebê e a mãe nunca 'sintonizam'. Neste ponto, a mãe pode ser vista como sendo teoricamente a responsável, ainda que, certamente, não se trate de uma acusação".

Na investigação da neurose, Winnicott (1945b/1997) percebeu que o bloqueio que impedia o desenvolvimento emocional tinha origem na infância inicial (dos 2 aos 4 anos de idade). Este sendo o período de explorar os relacionamentos 
interpessoais intensos, no qual se desperta a ansiedade mais severa. Essa ansiedade leva a um estabelecimento de defesas nos indivíduos, como a inibição. Nesse período, é fundamental que a criança tenha pessoas e um ambiente satisfatório, porque serão usadas pela criança em crescimento, como ideais para o processo de construção de uma lei moral.

Será por uma boa relação entre mãe-filho que o ego da criança irá se tornar forte, capacitando a criança a organizar defesas e desenvolver padrões pessoais marcados por tendências hereditárias. Caso isso não ocorra, é provável que se possam ocorrer reaçôes a colapsos ambientais e "os bebês que recebem apoio egoico inadequado ou patológico tendem a apresentar padrōes de comportamento semelhantes (inquietude, stranhamento, apatia,inibição, complacência)" (Winnicott, 1965c/2011, p. 24-25).

Assim, uma inibição pode ocorrer quando o bebê ainda não está integrado, no estado de dependência absoluta ou relativa, em que a mãe deve atender às necessidades de seu bebê para efetuar progressos pessoais, um crescimento emocional sadio e proporcionar o sentimento de continuidade do ser. Para que as falhas não ocorram, é importante que a mãe não somente esteja presente e atenta para atender às necessidades do lactente como também tenha um olhar especial para ele, vendo, investindo e considerando-o como um ser com potencial.

Winnicott (1947b/1982) não faz referência somente ao atendimento das necessidades do bebê no âmbito dos cuidados fisiológicos, mas principalmente no âmbito dos aspectos psicológicos:

Nas questões do corpo é possível cometer erros, admitir até raquitismo, e mesmo assim criar um filho sem coisa pior que umas pernas tortas. Mas do lado psicológico, um bebê privado de algumas coisas correntes, mas necessárias, como um contato afetivo, está vetado, até certo ponto, a perturbaçōes no seu desenvolvimento emocional que se revelarão através de dificuldades pessoais, à medida que crescer (p. 95-96).

Posteriormente, a fisiologia funde-se com a psicossomática e, inicialmente, ocorrem os controles advindos do processo de socialização e, em seguida, os controles e inibiçóes patológicas, associadas à repressão e aos conflitos inconscientes (Winnicott, 1988, p. 45).

Neste momento, no início do desenvolvimento emocional, a origem da inibição foi compreendida como acontecimentos que se referem a necessidades do bebê não atendidas, quando ao bebê ainda não está integrado; no entanto, em momentos posteriores a esse, a inibição também pode ocorrer, mesmo que a criança já tenha conquistado uma integração em termos da sua unidade psíquica, como um ser diferenciado do mundo. 
Nessa perspectiva, a proteção excessiva da mãe nesse período de integração da criança também pode levar a uma inibição. Winnicott (1938/1982) acredita que "pode ocorrer uma proteção tão grande da mãe que a criança se torna inibida ou se retrai” (p. 115). É comum algumas mães tentarem suprir constantemente as necessidades de seu filho, que, em certos momentos, não lhe permite explorar o mundo, a ter descobertas e a experimentar, o que o impede de ser espontâneo e criativo.

Winnicott (1965b/2011) acredita que algumas mães funcionam em dois níveis. Num primeiro, querem que as suas crianças cresçam, encontrem o mundo, sejam independentes; e, num outro, não concebem a ideia de deixar seu filho ir. Não conseguindo, todavia, abdicar de sua função materna, pois "é mais fácil para ela sentir-se maternal quando seu bebê é dependente do que quando, pelo crescimento, ele já começa a gostar de ser separado, independente e desafiador" (p. 53).

Após o período da infância, a sociedade também encontra dificuldade e intolerância para lidar com essas crianças que cresceram: os adolescentes. Um exemplo é a não aceitação de deixá-los livres para experimentar o novo. Assim, considera-se ideal crianças que sejam "boas". "O 'bom' na adolescência significa 'não se engajar irrefletidamente em relacionamentos'. O 'irrefletido', aqui, refere-se a gestações descuidadas e filhos ilegítimos. Muitos jovens vivem sua adolescência de modo um tanto quanto inibido" (Winnicott, 1961/2011, p. 65, grifos do autor).

Tal inibição pode ocorrer por privar o adolescente de se sentir livre, de fazer escolhas, de ser espontâneo, não permitindo o amadurecimento e as experiências da nova etapa desse desenvolvimento. Nesse momento, o surgimento de uma inibição pode ser considerado como uma falha da sociedade, a qual impõe aos adolescentes que não se comportem como crianças, pois estão saindo dessa fase, e que ajam como adultos. Contudo os jovens deixam de experienciar ou desafiar a continuidade do próprio crescimento e as novas experiências.

Assim, temos os seguintes momentos e as seguintes falhas que podem gerar uma inibição:

a) quando o bebê ainda não alcançou a integração, no estado de dependência absoluta ou relativa, pelas necessidades do bebê que não foram atendidas; $\mathrm{e}$

b) quando a criança já está integrada, mas ocorre um excesso de proteção da mãe ou um impedimento das novas descobertas do mundo, do gesto espontâneo, acarretando, portanto, nesses dois momentos, uma inibição como defesa. 


\section{OS DIVERSOS TIPOS DE INIBIÇÃO}

Após a compreensão da gênese da inibição (oriunda principalmente no início do desenvolvimento do bebê) e da função da inibição (como uma organização de defesa contra ansiedades e conflitos inconscientes), serão apresentados alguns tipos de inibição encontrados nas referências de Winnicott a esse fenômeno, a saber, a inibição da instintualidade, da agressividade, do brincar, da alimentação, do amor, da voracidade, da sexualidade, do impulso e intelectual.

\subsection{Inibição da instintualidade}

Winnicott (1955/2000) acredita que a inibição dos instintos é "uma das defesas contra as ansiedades depressivas" (p. 369), que resulta na diminuição de todas as consequências das experiências instintivas.

Assim, as principais defesas contra a ansiedade intolerável provocada pelos conflitos inconscientes vinculados à vida instintiva são de vários tipos: "o próprio instinto é inibido e torna-se inaceitável para o eu total, ou passa a ser aceito somente em condições que tornam a sua satisfação periclitante" (Winnicott, 1958c/2000, p. 419).

Quando a mãe deixa de exercer a sua função, ou seja, quando não atende às necessidades do bebê, a consequência é "a inibição dos instintos e um empobrecimento geral da personalidade e em seguida também uma perda da capacidade para sentir culpa" (Winnicott, 1955, p. 316).

$\mathrm{O}$ autor acrescenta que, sem o sentimento de culpa, a criança pode ter prazeres sensuais instintivos, no entanto perderá a capacidade de amar com afeição, podendo ocorrer uma inibição no amor. Aqui, uma inibição (instintual) poderá levar a outra (inibição no amor).

No estágio de dependência absoluta, a mãe é de suma importância para apresentar o mundo ao seu bebê. Caso isso não ocorra, o bebê também poderá se inibir diante de suas necessidades biológicas como a ocorrência de uma inibição da instintualidade, da alimentação.

Caso o bebê não se sinta envolvido na relação com sua mãe, o processo de integração poderá ser anulado, "de modo que a vida instintual torna-se inibida ou então dissociada da relação geral da criança com os cuidados que lhe são fornecidos" (Winnicott, 1984b, p. 151-152). O bebê perderá ou não conseguirá sentir vitalidade, não conseguirá se integrar e terá dificuldades nos relacionamentos interpessoais. 
Durante o período de socialização da criança, os instintos são manejados através de autocontrole, isto é, quando houver um conflito da psique com as exigências do instinto e da realidade externo ou social, haverá um prejuízo que poderá acarretar grandes danos, portanto "o conflito entre o impulso e o Ego ideal encontra-se no inconsciente reprimido, as inibições, compulsóes e ansiedades resultantes são mais cegas, menos capazes de se adaptar às circunstâncias, e mais danosas para o corpo e suas funções e processos" (Winnicott, 1988, p. 43).

Portanto se pode compreender que a inibição do instinto ocorre entre o conflito das funçôes corporais com as exigências do mundo externo, podendo irromper no processo de desenvolvimento do andar, de falar, de se alimentar, entre outros, possibilitando o surgimento de um novo tipo de inibição. Além disso, pode-se compreender que esse tipo de inibição é mais propício ocorrer quando o bebê ainda não está integrado.

\subsection{Inibição da agressividade}

Para Winnicott (1964/1982), a agressividade tem dois significados. Um se refere a uma reação direta ou indireta diante de uma frustração, e outro se refere as muitas fontes de energia do indivíduo.

Algumas crianças tendem a ver seus próprios impulsos agressivos controlados na agressão de outros. Todavia esse processo fornece à criança expectativas de perseguição, tornando a agressiva uma autodefesa contra ataques impensáveis. Por outro lado, em uma criança nitidamente agressiva que se relaciona com uma que não exerce a agressividade, ocorre certo grau de inibição de todos os impulsos, ou seja, a criança não terá capacidade criadora, uma vez que "esta se acha vinculada à irresponsabilidade infantil e a uma existência sem cuidados nem preocupações". Já na criança sadia, esta desenvolverá a capacidade para se colocar na situação de outra pessoa e se identificar com objetos externos (Winnicott, 1964, p. 265).

O autor acredita que esse é um processo difícil e que leva tempo para que o bebê consiga controlar suas ideias e excitações agressivas, sem perder a capacidade para ser agressivo em momentos adequados, tanto no ódio quanto no amor. Caso ele não obtenha esse equilíbrio, pode-se entender que uma inibição da agressividade advirá.

Por esse elemento agressivo nos impulsos de amor excitado, por exemplo, e a estes associados, o bebê sente a vida como algo perigoso e, portanto, "a maioria dos indivíduos torna-se inibida, em certo grau” (Winnicott, 1949/1982, p. 122). 
Segundo Winnicott (1957/2012), o bebê que pode machucar ou sente impulso para essa ação encontra-se na existência de uma inibição dos impulsos agressivos.

O que se espera é que a criança seja capaz de ser destrutiva, odiar, agredir e gritar, em vez de aniquilar o mundo; só assim será possível "encarar a agressão concreta como uma realidade positiva”. Para tanto, a mãe terá de ter paciência e tempo suficiente para os processos de maturação e para possibilitar que a criança desenvolva essa capacidade (Winnicott, 1964, p. 270).

A inibição da agressividade pode ocorrer principalmente após a criança ter conquistado a integração, quando esta tem capacidade para reconhecer o outro e identificar os objetos externos.

\subsection{Inibição no brincar}

De acordo com Winnicott (1968/1975), o brincar facilita o crescimento, conduz aos relacionamentos grupais e pode ser uma forma de comunicação na psicoterapia, tanto a favor da comunicação consigo mesmo quanto com os outros. Além disso, o brincar tem um tempo e um lugar, o qual o autor denominou espaço potencial. Esse espaço se relaciona com o mundo interno da criança e com a realidade concreta, ou externa, e implica confiança.

Quando falamos de brincar, não nos referimos apenas às crianças, mas também aos adultos. Podemos encontrar o brincar dos adultos nas escolhas das palavras, nas inflexões de voz e até mesmo no senso de humor (Winnicott, 1968/1975).

As crianças brincam por prazer, para dominar angústias, controlar ideias ou impulsos não dominados que levem à angústia. No entanto, se a excitação corporal for intensa ou se um grau de ansiedade for insuportável, o brincar destruir-se-á, pois a criança terá o sentimento de ameaça de existir como pessoa, tornando impossível o brincar. Ademais, o autor afirma que é no brincar, e, possivelmente, apenas no brincar, que "a criança ou o adulto fruem sua liberdade de criação" (p. 79). E é sendo criativo que o indivíduo descobre o eu. Logo, se há uma inibição no brincar, a criança é incapaz de continuar sendo, há uma interrupção do desenvolvimento emocional, na busca do eu, e a consequência é a incapacidade de fazer, de ser criativo (Winnicott, 1942/1982).

Winnicott (1947a/1982) também acredita que as brincadeiras são enriquecidas pelas ideias e pelos simbolismos sexuais, porém, "se houver uma forte inibição sexual, seguir-se-á uma inibição lúdica” (p. 171).

Nesse tipo de inibição, assim como na inibição dos instintos, é possível o surgimento de uma nova inibição no desenvolvimento da criança a partir de outra, além de poder ocorrer quando a criança já está integrada. 


\subsection{Inibição da alimentação}

Esse tipo de inibição foi um dos mais encontrados na obra de Winnicott. O autor cita, diversas vezes, a inibição da alimentação e dá exemplos clínicos para expor o fenômeno.

Segundo Winnicott (1945a/1982), a alimentação da criança se refere à relação mãe-filho. Esse ato é a prática da relação de amor entre esses dois indivíduos. Somente após o estabelecimento da confiança um no outro é que a alimentação começa a cuidar de si própria, ou seja, se a relação da mãe e de seu bebê teve início e houve um desenvolvimento emocional natural, não será preciso nenhuma técnica alimentar (quantidade, horários). O bebê tomará a porção certa de leite no ritmo adequado e saberá o momento de parar.

Winnicott (1958b/2000) encontrou frequentemente inibições ligeiras ou severas da alimentação, geralmente iniciando a perda de apetite na primeira infância. Algumas situações ou fases em que pode surgir uma inibição da alimentação durante o desenvolvimento do bebê são: o nascimento de um novo bebê, a perda da primeira pessoa que amamentava o bebê, o afastamento de casa, a primeira refeição com ambos os pais, as tentativas de induzir a criança a comer sozinha, a introdução de alimento sólido ou simplesmente mais consistente, as reaçôes ansiosas a mordidas no bico do seio (p. 92).

Além disso, o nascimento dos dentes também pode ocasionar a perda de apetite ou a recusa em aceitar tudo o que for novo (Winnicott, 1948). Essas são algumas das causas da falta de apetite, vinculadas a uma defesa contra a ansiedade e a depressão.

$\mathrm{O}$ autor acredita que "a maneira de fazer com que o bebê se iniba quanto ao mamar ao seio e, na verdade, quanto à alimentação em geral, é apresentar o seio ao bebê sem lhe dar qualquer chance de ser o criador do objeto que precisa ser encontrado" (Winnicott, 1988, p. 124). É importante a mãe apresentar os alimentos novos, proporcionando-os na medida da capacidade da criança de se relacionar com eles, para que não haja uma recusa. Além disso, caso a refeição de um bebê seja fornecida de modo mecânico, sem constituir uma experiência enriquecedora para o bebê, poderá interromper nele a sensação de continuar sendo e, consequentemente, poderá surgir uma inibição da alimentação.

Portanto, em condiçôes extremas, "uma criança de qualquer idade pode tornar-se tão ativamente inibida quanto à alimentação que o resultado vem a ser fatal. Entre um saudável capricho e uma inibição patológica, todas as gradações são possíveis" (Winnicott, 1988, p. 40). Por isso é importante a atenção dos pais no início do desenvolvimento de seus filhos, pois, conforme alguma situação ou o modo como for apresentado os alimentos ao bebê, poderá surgir esse tipo de defesa. 
A partir das situações em que pode ocorrer a inibição da alimentação, podese compreender que esse fenômeno pode surgir tanto no período inicial do desenvolvimento emocional, quando, por exemplo, ainda está sendo apresentado o seio, sem que o bebê reconheça que esse seio existe e não foi criado por ele, quanto no período posterior, quando a criança reconhece o EU diferenciado do mundo.

\subsection{Inibição no amor}

Geralmente, as crianças que constroem com esse tipo de defesa necessitam de um pai rigoroso, que também pode ser carinhoso, mas essencialmente deve ser severo e forte, uma autoridade que possa pôr limites, quando esta se encontra em estado de excitação. Apenas quando essa figura paterna está em evidência "é que a criança recupera seus primitivos impulsos amorosos, seu sentimento de culpa e seu desejo de corrigir-se" (Winnicott, 1946a/1982, p. 258). Caso contrário, essas crianças somente poderão se tornar cada vez mais inibidas no amor e, consequentemente, mais deprimidas e despersonalizadas, acabando por serem incapazes de sentirem a realidade das coisas, exceto a realidade da violência.

Com o amadurecimento (integração) no percurso do processo de desenvolvimento emocional, os sentimentos de amor e de ódio passam a ser vividos em conjunto (e não de forma cindida ou separada), unidos, ou seja, relacionados e, ou, dirigidos a um mesmo objeto. Nesse contexto o ciúme, se vivido em intensidade maior do que a que o indivíduo pode administrar (mantendo unidos o amor e o ódio sem ela mesma cindir-se ou desintegrarse), pode levar à inibição da capacidade de amar (Winnicott, 1982). Pode-se compreender que a dificuldade da criança de demonstrar ou receber afeto são sintomas de uma defesa, como da inibição do amor, advindo das necessidades do bebê de ter sido cuidado tanto no período de dependência absoluta, quando o bebê ainda não está integrado, quanto após ter adquirido essa integração.

É importante os pais tolerarem as ideias e as tensões advindas da ambivalência do amor e do ódio da criança, pois, assim, ela conseguirá chegar a esse ponto de seu desenvolvimento físico e emocional, capaz de tolerar os sentimentos mais intensos, sem precisar construir defesas contra a ansiedade, tal como uma inibição.

\subsection{Inibição da voracidade}

Novamente, retomando a importância da criança em integrar-se, pelos cuidados da mãe e pelas experiências instintivas que tendem a aglutinar a 
personalidade a partir de dentro, o processo de integração pode ser adiado devido à inibição precoce do ataque voraz. Winnicott (1945c) diz que,

Na vida normal do bebê, ocorrem longos períodos de tempo nos quais o bebê não se importa em ser uma porção de pedacinhos ou um único ser, nem se ele vive no rosto da mãe ou em seu próprio corpo, desde que de tempos em tempos ele se torne uno e sinta alguma coisa (p. 224).

Winnicott (1958a) distingue a sofreguidão da voracidade, uma vez que o termo voracidade é utilizado nas formulações teóricas sobre as exigências instintivas feitas à mãe pela criança, no período de aceitação inicial do princípio de realidade.

Num certo momento, a criança cessa de manifestar-se ansiosa por alimento, ganhando assim paz de espírito, mas perdendo a avidez. Surge, então, uma inibição da avidez saudável, uma vez que ela perda a plena satisfação de experimentar. Nesse momento, é importante a mãe acompanhar o sintoma para continuar atuando de um modo natural para contorná-lo (Winnicott, 1946b/1982).

\subsection{Inibição da sexualidade}

A inibição sexual pode acarretar prejuízos tanto na vida infantil quanto na adulta. Há brincadeiras sexuais relacionadas, em maior ou em menor grau, à fantasia sexual, assim, "uma criança sexualmente inibida é um fraco companheiro e está empobrecida, tal como um adulto sexualmente inibido" (Winnicott, 1947a, p. 174).

Quando a masturbação acompanha as ideias sexuais de um modo sem ser muito notada, a criança não encontra problemas para lidar com esse fenômeno. Entretanto se encontram problemas quando há relação da compulsão para a masturbação com a inibição das sensações sexuais. Desse modo, “a criança fica exausta por seus esforços por produzir satisfação e um clímax que não pode facilmente atingir. Desistir envolve uma perda do sentido de realidade ou do sentido de valor" (Winnicott, 1947a, p. 179).

Caso a sexualidade da criança seja imatura, perturbada ou inibida ao final do período de relacionamentos interpessoais, ela ressurgirá da mesma forma na puberdade, imatura, perturbada e inibida (Winnicott, 1988).

O relacionamento entre os seres humanos totais, já integrados, tem maior possibilidade de surgir na intenção de "um jogo sexual inibido ou num comportamento afetivo com ênfase na dependência ou independência" 
(Winnicott, 1962/2012, p. 166). Nesse momento de integração, os adolescentes precisam encontrar alívio para a tensão sexual, o que resulta na compulsão à masturbação.

No entanto, muitas vezes, esse indivíduo é proibido de encontrar esse alívio, tanto pela falta de sentido quanto pelo impedimento do ambiente, por não compreender essa necessidade, que é natural do desenvolvimento do indivíduo. Assim, uma das consequências pode ser o surgimento de uma inibição sexual.

\subsection{Inibição do impulso}

De acordo com Winnicott (1945c), uma criança que mantém a agressão dentro dela, permanecendo tensa, séria, tentando manter a todo o momento o controle, adquire certo grau de inibição dos impulsos, podendo afetar a capacidade de criar.

Outro aspecto que possibilita o surgimento de uma inibição do impulso é a inconfiabilidade da figura materna: "O sentimento de culpa fica intolerável e a criança é pressionada a retroceder para a inibição, ou perda do impulso que é, de fato, parte do amor primitivo" (Winnicott, 1984a/2012, p. 123).

Nesse momento, a confiança na figura materna é imprescindível, já que o bebê necessita sentir que o objeto, ou a mãe, sobrevive a seus ataques, a suas fantasias, para trazer o sentido de alívio e de que é possível viver em um lugar no qual não se sinta perdido, ou seja, quando há uma integração e a criança consegue reconhecer o objeto externo, ou seja, a mãe.

Winnicott (1989/1994) afirma que, na inibição do impulso, há uma perda da pulsão instintual no relacionamento com objetos, levando a um empobrecimento da experiência de vida da criança. Tal empobrecimento pode acarretar outro tipo de inibição, como visto anteriormente.

\subsection{Inibição intelectual}

A inibição intelectual, muitas vezes, é confundida com debilidade mental ou autismo. Winnicott (1988) acredita que não há sentido no termo "saúde intelectual", uma vez que, tanto o intelecto quanto a psique dependem de um funcionamento de um órgão do corpo, nesse caso, o cérebro. A base do intelecto é a qualidade do cérebro. Durante um tratamento de distúrbio mental, o neurocirurgião corta o cérebro, resultando numa inibição de defesas contra a loucura. Dessa forma, o intelecto é atingido ou os processos mentais são modificados, mesmo que o corpo permaneça sadio. 
$\mathrm{O}$ autor distingue o intelectual do emocional, uma vez que,

No curso do desenvolvimento emocional, mesmo seu curso normal, frequentemente envolve inibições intelectuais: as ansiedades também envolvem coerção intelectual, produzindo uma criança que precisa saber, que precisa ser ótima aluna, e para a qual o desenvolvimento intelectual é mais uma questão de defesa contra sentir-se mal do que uma questão de prazer (Winnicott, 1996/1997, p. 77, grifos do autor).

Winnicott (1988) acredita que a inibição para o uso da aritmética é decorrente da inabilidade de a criança começar a formular o conceito de um, de unidade, do self. $\mathrm{O}$ autor diz que

É bem conhecido o fato de que a incompetência para lidar com a aritmética mais simples de modo algum implica na incapacidade para cálculos mentais abstratos extremamente complexos, e de fato pode haver uma correlação entre o uso exagerado do raciocínio matemático abstrato e uma inibição das funçôes mais simples de adição e subtração (p. 138).

Nesse sentido, a inibição intelectual não diz respeito apenas às dificuldades cognitivas, vai além, refere-se à impossibilidade de continuar sendo, de o indivíduo se tornar uma pessoa inteira, uma vez que há a expectativa da sociedade para o indivíduo ser bom, sem poder levar em conta suas falhas e necessidades.

\section{CONSIDERAÇŌES FINAIS}

O objetivo desta pesquisa foi compreender a inibição no desenvolvimento do indivíduo, à luz da teoria do desenvolvimento, na obra de Winnicott, para explicitar sua gênese, sua dinâmica e os possíveis tipos de inibição.

Assim, possibilitou compreender que as fases mais primitivas do desenvolvimento emocional são as mais suscetíveis ao uso de uma inibição como uma defesa contra a angústia. Essa inibição dependerá do conflito que o bebê experienciará para se formar um tipo específico de inibição, podendo ser tanto por uma falta quanto por um excesso de cuidado. Assim, a consideração da provisão ambiental (especialmente aquilo que a mãe pode fornecer) tem uma importância decisiva.

Ademais, esse fenômeno surge como uma defesa contra uma ansiedade emocional, ou diante de um conflito, e é importante ressaltar que nem sempre inibição resulta numa patologia. Winnicott acredita que somente uma criança saudável é capaz de organizar defesas, como a inibição, para lidar com os conflitos inconscientes. 
Tal compreensão nos leva a acreditar que uma inibição pode transformar a vida criativa do indivíduo em um mundo pobre, pois essa defesa impossibilita seu gesto espontâneo, de ser e continuar sendo.

Pela apresentação de diferentes tipos de inibição na obra de Winnicott, também se verificou que uma inibição específica pode acarretar o surgimento de outra, ou seja, uma criança pode apresentar uma inibição dos instintos, podendo desenvolver uma inibição específica da alimentação, por exemplo. 


\section{REFERÊNCIAS}

Freud, A. (1946). O ego e os mecanismos de defesa. Rio de Janeiro: Civilização Brasileira, 1978. (Publicado originalmente em 1946).

Freud, S. (1925). Um estudo autobiográfico: inibições, sintomas e ansiedades, análise leiga e outros trabalhos (1925-1926). In J. Salomão (Trad.), Edição standard brasileira das obras psicológicas completas de Sigmund Freud. (Vol. 20). Rio de Janeiro: Imago, 2006. (Publicado originalmente em 1925).

Santiago, A. L. (2005). A inibição intelectual na psicanálise. Rio de Janeiro: Jorge Zahar.

Winnicott, D. W. (1938). Timidez e perturbações nervosas nas crianças. In D. W. Winnicott, A criança e o seu mundo. (pp. 238-242). Rio de Janeiro: LTC, 1982. (Publicado originalmente em 1938).

Winnicott, D. W. (1939). Evacuação de crianças pequenas. In D. W. Winnicott, Privação e delinquência. (pp. 9-18). São Paulo: Martins Fontes, 2012. (Publicado originalmente em 1939).

Winnicott, D. W. (1942). Por que as crianças brincam? In D. W. Winnicott, A criança e o seu mundo. (pp. 64-75). Rio de Janeiro: LTC, 1982. (Publicado originalmente em 1942).

Winnicott, D. W. (1945a). Alimentação do bebê. In D. W. Winnicott, $A$ criança e o seu mundo. (pp. 31-36). Rio de Janeiro: LTC, 1982. (Publicado originalmente em 1945).

Winnicott, D. W. (1945b). Para um estudo objetivo da natureza humana. In D. W. Winnicott, Pensando sobre crianças. (pp. 31-37). Porto Alegre: Artmed, 1997. (Publicado originalmente em 1945).

Winnicott, D. W. (1945c). Desenvolvimento emocional primitivo. In D. W. Winnicott, Da pediatria à psicanálise. (pp. 218-232). Rio de Janeiro: Imago, 2000. (Publicado originalmente em 1945).

Winnicott, D. W. (1946a). Aspectos da delinquência juvenil. In D. W. Winnicott, A criança e o seu mundo. (pp. 256-261). Rio de Janeiro: LTC, 1982. (Publicado originalmente em 1946).

Winnicott, D. W. (1946b). O que entendemos por uma criança normal?. In D. W. Winnicott, A criança e o seu mundo. (pp. 140-147). Rio de Janeiro: LTC, 1982. (Publicado originalmente em 1946). 
Winnicott, D. W. (1947a). A criança e o sexo. In D. W. Winnicott, A criança e o seu mundo. (pp. 166-182). Rio de Janeiro: LTC, 1982. (Publicado originalmente em 1947).

Winnicott, D. W. (1947b). Mais ideias sobre os bebês como pessoas. In D. W. Winnicott, A criança e o seu mundo. (pp. 95-103). Rio de Janeiro: LTC, 1982. (Publicado originalmente em 1947).

Winnicott, D. W. (1948). Pediatria e psiquiatria. In D. W. Winnicott, Da pediatria à psicanálise. (pp. 233-253). Rio de Janeiro: Imago, 2000. (Publicado originalmente em 1948).

Winnicott, D. W. (1949). As crianças e as outras pessoas. In D. W. Winnicott, A criança e o seu mundo. (pp. 116-126). Rio de Janeiro: LTC, 1982. (Publicado originalmente em 1949).

Winnicott, D. W. (1953). A mãe, a professora e as necessidades da criança. In D. W. Winnicott, A criança e o seu mundo. (pp. 214-224). Rio de Janeiro: LTC, 1982. (Publicado originalmente em 1953).

Winnicott, D. W. (1955). A posição depressiva no desenvolvimento emocional normal. In D. W. Winnicott, Da pediatria à psicanálise. (pp. 355-373). Rio de Janeiro: Imago, 2000. (Publicado originalmente em 1955).

Winnicott, D. W. (1957). Agressão e suas raízes. In D. W. Winnicott, Privação e delinquência. (pp. 93-110). São Paulo: Martins Fontes, 2012. (Publicado originalmente em 1957).

Winnicott, D. W. (1958a). A tendência antissocial. In D. W. Winnicott, Da pediatria à psicanálise. (pp. 406-416). Rio de Janeiro: Imago, 2000. (Publicado originalmente em 1958).

Winnicott, D. W. (1958b). O apetite e os problemas emocionais. In D. W. Winnicott, Da pediatria à psicanálise. (pp. 91-111). Rio de Janeiro: Imago, 2000. (Publicado originalmente em 1958).

Winnicott, D. W. (1958c). Pediatria e neurose infantil. In D. W. Winnicott, Da pediatria à psicanálise. (pp. 417-423). Rio de Janeiro: Imago, 2000. (Publicado originalmente em 1958).

Winnicott, D. W. (1961). Fatores de integração e desintegração na vida familiar. In D. W. Winnicott, A família e o desenvolvimento individual. (pp. 59-72). São Paulo: Martins Fontes, 2011. (Publicado originalmente em 1961). 
Winnicott, D. W. (1962). A luta para superar depressões. In D. W. Winnicott, Privação e delinquência. (pp. 163-176). São Paulo: Martins Fontes, 2012. (Publicado originalmente em 1962).

Winnicott, D. W. (1963). O desenvolvimento da capacidade de envolvimento. In D. W. Winnicott, Privação e delinquência. (pp. 111-118). São Paulo: Martins Fontes, 2012. (Publicado originalmente em 1963).

Winnicott, D. W. (1964). As raízes da agressividade. In D. W. Winnicott, $A$ criança e o seu mundo. (pp. 262-270). Rio de Janeiro: LTC, 1982. (Publicado originalmente em 1964).

Winnicott, D. W. (1965a). Da dependência à independência no desenvolvimento do indivíduo. In D. W. Winnicott, $O$ ambiente e os processos de maturação. (pp. 79-87). Porto Alegre: Artmed, 1983. (Publicado originalmente em 1965).

Winnicott, D. W. (1965b). A criança de cinco anos. In D. W. Winnicott, $A$ familia e o desenvolvimento individual. (pp. 49-58). São Paulo: Martins Fontes, 2011. (Publicado originalmente em 1965).

Winnicott, D. W. (1965c). O relacionamento inicial entre uma mãe e seu bebê. In D. W. Winnicott, A família e o desenvolvimento individual. (pp. 21-28). São Paulo: Martins Fontes, 2011. (Publicado originalmente em 1965).

Winnicott, D. W. (1968). O Brincar: Uma exposição teórica. In D. W. Winnicott, $O$ brincar e a realidade. (pp. 59-78). Rio de Janeiro: Imago. (Publicado originalmente em 1968).

Winnicott, D. W. (1984a). A ausência de um sentimento de culpa. In D. W. Winnicott, Privação e delinquência. (pp. 119-126). São Paulo: Martins Fontes, 2012. (Publicado originalmente em 1984).

Winnicott, D. W. (1984b). A psicologia da separação. In D. W. Winnicott, Privação e delinquência. (pp. 149-152). São Paulo: Martins Fontes, 2012. (Publicado originalmente em 1984).

Winnicott, D. W. (1988). Natureza humana. Rio de Janeiro: Imago. 
Winnicott, D. W. (1989). Psiconeurose na infância. In C. Winnicott, R. Shepherd \& M. Davis (Orgs.), Exploraçōes psicanalíticas: D. W. Winnicott. (pp. 53-58). Porto Alegre: Artmed, 1994. (Publicado originalmente em 1989).

Winnicott, D. W. (1993). Ciúme. In D. W. Winnicott, Conversando com os pais. (pp. 49-76). São Paulo: Martins Fontes, 1999. (Publicado originalmente em 1993).

Winnicott, D. W. (1996). Higiene mental da criança pré-escolar. In D. W. Winnicott, Pensando sobre crianças. (pp. 75-88). Porto Alegre: Artmed, 1997. (Publicado originalmente em 1996). 